\title{
Hepatoprotective effect of mulberry (Morus nigra) leaves extract against methotrexate induced hepatotoxicity in male albino rat
}

\author{
Hend M. Tag
}

\begin{abstract}
Background: Drug-induced liver injury is a major health problem that challenges not only health care professionals but also the pharmaceutical industry and drug regulatory agencies. The possible hepatoprotective effect of the administration of mulberry ethanolic extract (MUL) leaves against hepatotoxic effect of the anti-rheumatic drug, methotrexate (MTX) was evaluated in this study both vivo (using animal models) and in vitro (human hepatoma HepG2 cells).
\end{abstract}

Methods: In the in-vivo study, 20 male albino rats were equally assigned into four groups; control group received distilled water orally; MUL treated-group received $500 \mathrm{mg} / \mathrm{kg} /$ day of MUL extract; MTX treated-group was injected with a single dose of $20 \mathrm{mg} / \mathrm{kg}$ MTX intraperitoneally on the 4th day; MUL-MTX treated-group received the previously mentioned doses of MUL and MTX (both control and MUL treated groups were administered a single dose of a physiological saline i.p.). At the end of the experimental period (14 days) activities of alanine transaminase (ALT), aspartate transaminase (AST), alkaline phosphatase (ALP) and lactate dehydrogenase (LDH) as well as total serum protein (TP) and albumin (ALB) levels were evaluated to assess liver function.

Results: A marked reduction in the viability of HepG2 cells was observed after $48 \mathrm{~h}$ with $\mathrm{IC}_{50}$ equal to $14.5 \mathrm{\mu g} / \mathrm{mL}$ of MUL administration. Treating the animals with MUL in combination with MTX mitigated liver injury, causing a significant reduction in activities of AST, ALT, ALP and LDH as compared to the MTX-group. The liver architecture revealed more or less normal appearance with the combined treatment when compared with MTX treatment alone.

Conclusions: This study recommends that the co-administration of MUL with MTX that may have therapeutic benefits against MTX-hepato-cytotoxicity.

Keywords: Mulberry leaf extract, Methotrexate, Hepatotoxicity, HepG2 cells

\section{Background}

Drug-induced liver injury is a major health problem that challenges not only health care professionals but also the pharmaceutical industry and drug regulatory agencies [1]. The drug-induced injury could be induced through different ways including direct toxic effect; immunological reaction or through active metabolite that is formed by the drug [2]. Methotrexate (MTX) drug, a structural analogue of folic acid, is widely used as anti-an rheumatic, cytotoxic chemotherapeutic agent for malignancies as well as in the treatment of various inflammatory diseases $[3,4]$. MTX is

Correspondence: hendmaarof1@yahoo.com

Zoology Department, Faculty of Sciences, Suez Canal University, Ismaillia 41522, Egypt actively accumulated in the liver where it is metabolized and stored in polyglutamated form, thus decreases folate levels by the inhibition of dihydrofolate reductase [5]. The widespread use of MTX and it is long-term therapy has attracted physicians' attention to the possible adverse reactions of MTX [6].

Traditional plant medicines or herbal formulations might offer a natural key to hepatoprotective effect against xenobiotic/drug [7]. Morus nigra (Moraceae) is widely distributed in Asia, Africa, Europe, and America, and it is commonly known as black mulberry. It has been reported that Morus nigra is antioxidant and has protective action against oxidative damage to membranes and biomolecules $[8,9]$. Important phyto-chemical constituents e.g. \\ () Biomed Central}

(C) 2015 Tag. This is an Open Access article distributed under the terms of the Creative Commons Attribution License (http:// creativecommons.org/licenses/by/4.0), which permits unrestricted use, distribution, and reproduction in any medium, provided the original work is properly credited. The Creative Commons Public Domain Dedication waiver (http://creativecommons.org/ publicdomain/zero/1.0/) applies to the data made available in this article, unless otherwise stated. 
flavonoids, alkaloids and phenols have been reported in this plant $[8,10]$. The flavonoids compound has shown to have hepatoprotective activity as reported previously by Adedosu et al. [11]. In addition, Naderi et al. [12] and Mallhi et al. [13] investigated the hepatoprotective effects of Morus nigra in both human and animals.

Therefore, the aim of the present work is to investigate the hepatoprotective effects of black mulberry leaf extract against the possible MTX-induced liver injury in human hepatoma HepG2 cells as well as in male albino rats.

\section{Methods}

\section{Chemicals and plant materials}

Methotrexate was purchased from Orion Corporation, Espoo, Finland. Other chemicals and reagents were of high analytical grade and were bought from standard commercial suppliers. The leaves of mulberry plant were collected from Ismaillia government, Egypt. The plant materials were identified from a taxonomist, Department of Botany, Faculty of Science, Suez Canal University, Ismailia, Egypt.

\section{Preparation of the plant extracts}

Plant material was collected from mulberry trees which cultivated in Faculty of Science, Suez Canal University, Ismailia, Egypt, in March 2014 and were identified and authenticated by Botany Department, Faculty of Science, Suez Canal University on the basis of taxonomic characters and by direct comparison with the herbarium specimens with a voucher number (HERBFAS\#5) available at the herbarium of Botany department. The plant extract was prepared as described before in $[14,15]$ with minor modifications. Briefly, the leaves of Morus nigra were washed, air-dried and powdered. The dried powder was extracted with $50 \%$ hydro-ethanol solution for $48 \mathrm{~h}$. The marc was further extracted by $50 \%$ hydro-ethanol for $48 \mathrm{~h}$ to obtain the extract. The extract was then filtered and evaporated to dryness under reduced pressure on a rotary evaporator. The yield of ethanolic extract of Morus nigra leaves was found to be $10.2 \% \mathrm{w} / \mathrm{w}$.

In vitro study: cytotoxicity evaluation using viability assay HepG2 cell line (human cell line of a well differentiated hepatocellular carcinoma isolate from a liver biopsy of a male Caucasian aged 15 years) was obtained from the American Type Culture Collection (ATCC). Cells were cultured in Dulbecco's Modified Eagle Medium (DMEM) with Earle's salts supplemented with $10 \%$ fetal bovine serum (Bio-Whittaker, Lonza, Belgium), $2 \mathrm{~m} \mathrm{M} \mathrm{L-glu-}$ tamine, $50 \mathrm{IU} / \mathrm{mL}$ streptomycin and maintained at $37^{\circ} \mathrm{C}$ in humidified $5 \% \mathrm{CO}_{2}$.

Doxorubicin hydrochloride, an anticancer drug (VHB, Medi-sciences, Ltd, India) was used in the present study as a positive control. The drug was used within 15 days of purchase and was stored at the prescribed temperature. The dilutions were made in phosphate buffer saline (PBS).

Cell viability was assessed after $48 \mathrm{~h}$ of incubation with mulberry leaf extract or doxorubicin hydrochloride (50.0, $25.0,12.50,6.25,3.12,1.56 \mu \mathrm{g} / \mathrm{mL}$ ) by crystal violet staining which dyes cellular nuclei. The staining was performed according to Henriksson et al. [16] method with slight modifications. Briefly, the cells were harvested, suspended in the growth medium mentioned above and seeded on 96-well plates (Falcon, NJ, USA) of $1 \times 10^{4}$ cells per well. After $24 \mathrm{~h}$, the cells were incubated at $37^{\circ} \mathrm{C}$ in a humidified incubator with $5 \% \mathrm{CO}_{2}$ for $48 \mathrm{~h}$ with mulberry leaf extract or doxorubicin hydrochloride. The medium was then removed and the cells were fixed in situ with $4 \%$ formaldehyde solution in PBS for $30 \mathrm{~min}$ at room temperature. The cells were washed twice with PBS (pH 7.4) and stained with $0.5 \%$ crystal violet dissolved in $25 \%$ aqueous solution of methanol for $5 \mathrm{~min}$ at room temperature. Unbound dye was washed out with deionized water and the cells allowed to air dry. The dye was solubilized in $33 \%$ aqueous solution of acetic acid while shaking for $30 \mathrm{~min}$ at room temperature. Optical density (OD) was measured with a microplate reader (TECAN, Inc.), at wavelength of $490 \mathrm{~nm}$.

\section{In vivo study \\ Animals and experimental design}

Twenty male albino rats weighing $180-200 \mathrm{~g}$ obtained from the animal house of National Research Center, Egypt were used. Rats were housed in an air-conditioned room with 12-h light and dark cycles at $22 \pm 2{ }^{\circ} \mathrm{C}$. They were fed standard rodent diet with tap water ad libitum. Animals were divided into 4 groups, 5 rats each. The experiment was performed in accordance with the internationally accepted standard ethical guidelines for laboratory animal use and care as described in the European Community guidelines [17].

The first group 'control-group' was untreated with neither MTX nor MUL. The second group 'MUL-group' received mulberry leaf extract intragastrically at a dose of $500 \mathrm{mg} / \mathrm{kg}$ daily for 14 days [13]. The third group was injected with a single dose of MTX (20 mg/kg, I.P.) [18] at the fourth day of the experiment, 'MTX-group'. The fourth group 'MUL+MTX-group' was administrated with MUL and MTX at the same does, described in second and third groups, respectively. Both control and MUL treated groups were administered a single dose of a physiological saline (IP). All animal treatments were conducted daily for 14 days.

\section{Sample collection}

At the end of the experiment, rats in all groups were anaesthetized with ether and blood samples were withdrawn from retro-orbital venous plexus by a capillary tube. 
Serum was separated followed by centrifugation at $4000 \mathrm{rpm}$ for $10 \mathrm{~min}$ and stored at $-20{ }^{\circ} \mathrm{C}$ until the biochemical analyses were performed. The animals were then euthanized by cervical dislocation before sacrificing. Livers were dissected out, blotted, dried and weighed. For each group livers were fixed in $10 \%$ formalin saline for routine histopathological examination.

\section{Assessment of hepatic function markers}

The activities of alanine aminotransaminase (ALT) and aspartate aminotransaminase (AST) were determined in serum using commercial kits (Human Company, Germany, Cat. No. EC 2.6.1.2), based on kinetic method of Schumann et al. [19]. Lactate dehydrogenase (LDH) activity was evaluated using the method of Young [20] (Biosystems Company, Spain, Cat. No. M11580i-10). Alkaline phosphatase (ALP) activity was determined using commercial kit (Pointe Scientific, Inc. Brussels, BELGIUM, Cat. No. P803-A751601), based on the recommended method of Tietz [21]. Total protein (TP) and albumin (ALB) levels were measured using commercial kits (Human Company, Germany, Cat. No. INF. 157001. GB and INF.156001.D, respectively).

\section{Morphometric and histopathological study}

Determination of hepatosomatic index The gross liver weight of each rat was determined using an electronic balance immediately after the freshly harvested liver was blotted dry. A hepatosomatic index (HSI) was computed by expressing the liver weight as a percentage of the rat's body weight at the end of the experiment [22].

Histopathological evaluation and image analysis Liver specimens were quickly removed, immersed in $10 \%$ formalin, dehydrated and embedded in paraffin, sectioned at $4 \mu \mathrm{m}$, stained with hematoxylin and eosin ( $\mathrm{H} \& \mathrm{E})$ and evaluated by light microscopy. The histopathological scoring analysis was performed according to Lobenhofer et al. [23], the assessment was expressed as the sum of the individual score grades from 1 (minimal), 2 (mild), 3 (moderate), to 4 (marked) for each of the following parameters from liver sections: hepatocyte necrosis, fibrosis (collagen deposition), cellular infiltration, hepatocyte apoptosis and hepatocyte fatty change.

Identifying and quantifying liver fibrosis The liver tissue samples were fixed in $10 \%$ neutral buffered formalin, embedded in paraffin, sectioned at $4 \mu \mathrm{m}$ thicknesses and stained with Goldner's Masson Trichrome for detection of collagen fibers.

Ten colored histological images resulting from Goldner's Masson Trichrome staining were captured by a digital camera (Canon Power Shot A640) and digitalized at 1024x 768 pixel, 24 bit/pixel resolution, from 10 non-overlapping random fields per histological section in randomly chosen three animals from each group, at $\times 200$ magnification. The digital images were processed using the image J (version $1.32 \mathrm{j}$, the national institution of health, USA) analysis software. The image $J$ automatically identifies and isolates fibrotic areas according to their staining (green) and then measures the area occupied by fibrosis with respect to the total liver area examined [24]. The percentage of area occupied by fibrosis (PF) is then determined, according to the following equation, $\mathrm{PF}=$ (labeled fibrosis area/total image area) $\times 100[25]$.

\section{Statistical analysis}

All values were expressed as mean \pm standard error $(\mathrm{X} \pm$ $\mathrm{SE}$ ). Comparisons of evaluated parameters between the experimental groups were made using the one-way analysis of variance (ANOVA). Post-hoc comparisons were conducted by Duncan procedure. Statistical analyses were performed with the Statistical Package for the Social Sciences (SPSS), version 20.0 for windows (SPSS Inc., Chicago, IL, USA), with a significant difference of $p<0.05$.

\section{Results}

Influence of MUL on viability of HepG2 cell line

The effects of ethanolic extract of Mulberry leaf against human HepG2 cells are shown in Fig. 1. Concentration above $12.5 \mu \mathrm{g} / \mathrm{mL}$ resulted in a marked reduction in cell viability. The percentage of growth inhibition was found to increase with increasing concentration of the test compound. The $\mathrm{IC}_{50}$ values of MUL and Doxorubicin hydrochloride found to be 14.5 and $1.2 \mu \mathrm{g} / \mathrm{mL}$ respectively.

\section{Effect of MUL extract on MTX-induced hepatotoxicity}

The biochemical parameters of AST, ALT, ALP, LDH activities as well as the levels of TP and ALB were measured to estimate the general liver function. As shown in Table 1, animals treated with MUL did not show noticeable changes compared with control group. Whereas, the administration of MTX induced hepatotoxicity indicated by the increase in

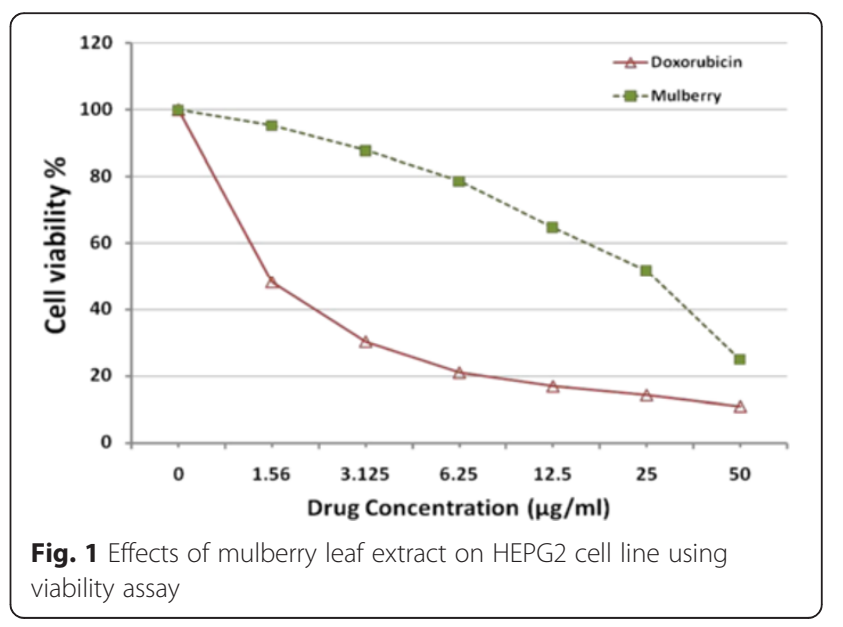


Table 1 Effects of ethanol extract of mulberry on various biochemical parameters in rats with chemically induced liver toxicity

\begin{tabular}{lccccccc}
\hline Groups & ALT activity (U/l) & AST activity (U/l) & ALP activity (U/l) & LDH activity U/l & Total protein g/dl & Albumin g/dl & $\begin{array}{c}\text { Albumin to Globulin Ratio. } \\
\text { (A/G) g/dl }\end{array}$ \\
\hline Control & $40.50 \pm 3.28$ & $93.25 \pm 2.36$ & $66.00 \pm 7.12$ & $470.50 \pm 9.14$ & $7.100 \pm 0.163$ & $4.13 \pm 0.16$ & $1.50 \pm 0.04$ \\
MUL & $19.50 \pm 1.19$ & $62.00 \pm 5.79$ & $36.25 \pm 9.25$ & $422.25 \pm 12.25$ & $7.00 \pm 0.73$ & $4.03 \pm 0.06$ & $1.43 \pm 0.03$ \\
MTX- & $71.00 \pm 12.34^{\mathrm{a}}$ & $135.75 \pm 25.55^{\mathrm{a}}$ & $110.25 \pm 13.82^{\mathrm{a}}$ & $1607.25 \pm 121.57^{\mathrm{a}}$ & $6.63 \pm 0.10$ & $3.83 \pm 0.33$ & $1.20 \pm 0.08$ \\
MUL+ MTX & $21.75 \pm 3.25^{\mathrm{b}}$ & $82.00 \pm 6.00^{\mathrm{b}}$ & $99.00 \pm 7.55^{\mathrm{b}}$ & $393.00 \pm 87.18^{\mathrm{b}}$ & $6.93 \pm 0.048$ & $3.70 \pm 0.29$ & $1.35 \pm 0.23$ \\
\hline
\end{tabular}

Values are expressed as mean \pm S.E. for five rats in each group

${ }^{a}$ Significantly different from control using one way ANOVA followed by Duncan

${ }^{b}$ Significantly different compared with MTX-treated group using one way ANOVA followed by Duncan

ALT, AST, ALP and LDH activities compared with control group. Serum total protein and albumin levels displayed no significant difference as compared with control. On the other hand, rats treated with both MUL and MTX in combination had significant decrease in ALT, AST and LDH activities compared with MTX group $(p<0.05)$.

Liver-body weight ratio (HSI) has been found to be significantly increased after MTX administration as compared with control group. However, there was no significant difference in HSI of MUL-MTX group when compared with control group, while there was apparent significant decrease in HSI values comparing MUL-MTX group with MTX-treated animals (Fig. 2).

Results from histopathological studies provided supportive evidence for the biochemical analysis. The 'control group' (Fig. 3a-b) and 'MUL group' (Fig. 3c-d) showed a normal appearance of the liver cells, whereas the MTX-treated animal showed changes in hepatic architecture with centrilobular hepatic necrosis, cloudy swelling of hepatocytes and cell infiltration associated with fibrosis around the portal tract (Fig. 3e and f). Treatment with $500 \mathrm{mg} / \mathrm{kg}$ b.wt ethanol extract of MUL showed moderate enhancement in protecting liver cells from MTX-injury as shown in Fig. 3g and $h$.

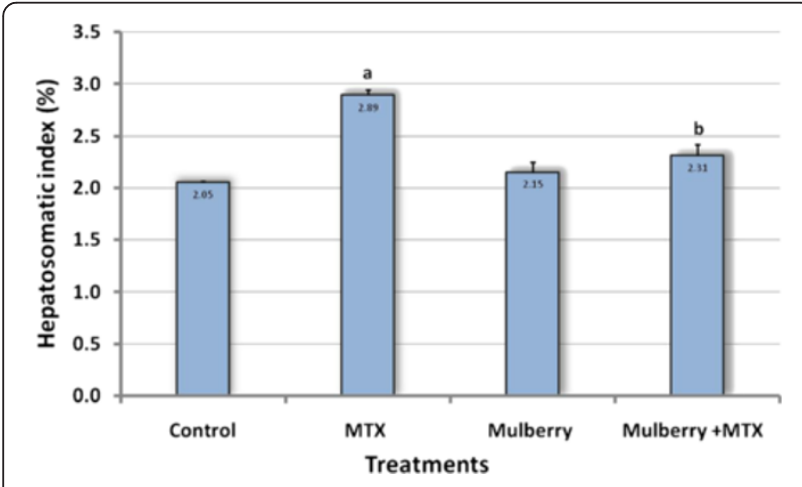

Fig. 2 Effect of mulberry leaf extract on the hepatosomatic index (HSI) of MTX treated rats. Results are expressed as mean \pm S.E. $(n=5)$, ${ }^{a}$ Significantly different from control using one way ANOVA followed by Duncan. ${ }^{b}$ Significantly different compared with MTX-treated group using one way ANOVA followed by Duncan. Hepatosomatic index: (Liver weight $\times 100$ )/body weight
The microscopic damage score for each group was determined, and illustrated in Fig. $3 \mathrm{i}-\mathrm{m}$. The hepatocyte degeneration for 'MTX group' $(22.7 \pm 0.33)$ and 'MTX-MUL group' $(5.0 \pm 1.15)$ was significantly increased compared with the 'control group' (Fig. 3i). The congestion in 'MTX group' ( $15.0 \pm 1.00)$ was significantly increased, compared with the control group $(0.00 \pm 0.00)$, while there was no significant difference between MTX-MUL group and control group observed (Fig. 3j). The leukocyte infiltration in MTX group $(25.33 \pm 1.76)$ was significantly increased as compared with control group. However, there was no significant difference between MTX-MUL (2.67 \pm $0.88)$ group and control group $(0.00 \pm 0.00)$ (Fig. $3 \mathrm{k})$. The fibrosis in MTX group $(35.0 \pm 0.58)$ was significantly increased than control group, whereas there was no significant difference between MTX-MUL group (2.33 \pm $1.45)$ and the control group $(0.00 \pm 0.00)$ (Fig. 3l). The total histopathology score for the liver was significantly increased in MTX-treated group $(120.3 \pm 1.76)$ compared with the control group $(18.0 \pm 3.21)$ (Fig. $3 \mathrm{~m}$ ), with no significant difference between MUL-group and control group.

The results obtained from histological sections of livers with Masson's Trichrome staining for control and MUL-treated rats were similar (Fig. 4a and b). The classic lobule was hexagonal in shape. The portal tract area was located at each corner of the lobule, and was composed of thin connective tissue septum containing few collagen fibers. Embedded in the portal tract there were a terminal portal venule, a terminal hepatic arteriole, an interlobular bile ductule and fine lymph vessels. The livers of the MTX treated animals showed an apparent increase in the amount of collagen fibers particularly around blood vessels in portal tract (Fig. 4c). Section of liver tissue from animals that were treated with combination of MTX and MUL showed less amount of collagen fibers (Fig. 4d) as compared with MTX-group. Quantification of fibrosis using semi-automated image analyses revealed a significant increase of fibrosis in liver of MTXtreated rats compared to control $(19.50 \pm 6.69 \%$ vs $1.33 \pm$ $1.51 \%$, Table 2), and a significant decrease in MTX-MUL group compared to MTX-treated rats $(2.64 \pm 2.15$ vs $19.50 \pm 6.69$, Table 2). 


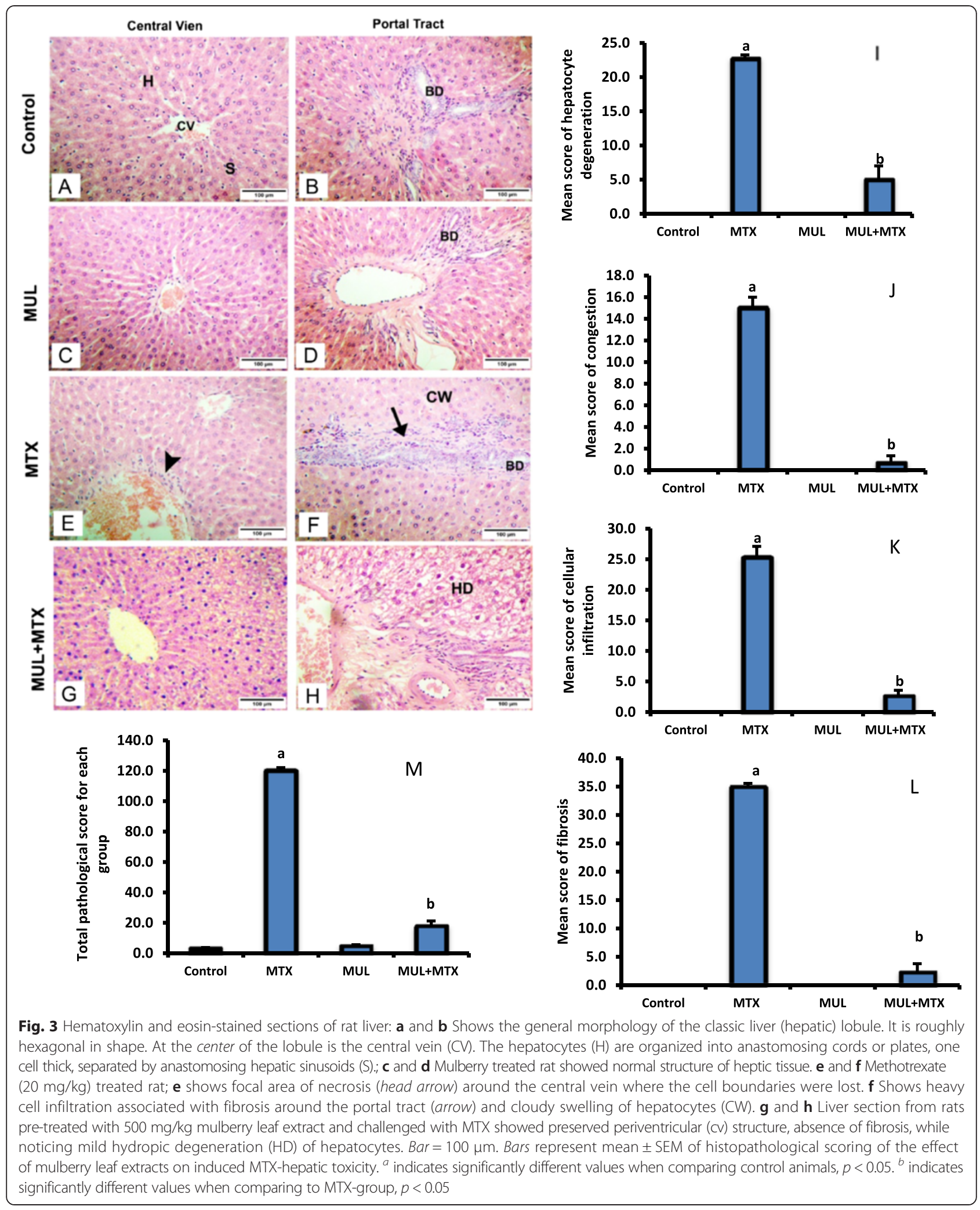

\section{Discussion}

Methotrexate (MTX), a folic acid antagonist, is widely used as a cytotoxic chemotherapeutic agent for several malignancies and various inflammatory diseases, which may lead to liver hepatotoxicity due to the depletion of the folate [26]. The results of the present study indicate that 

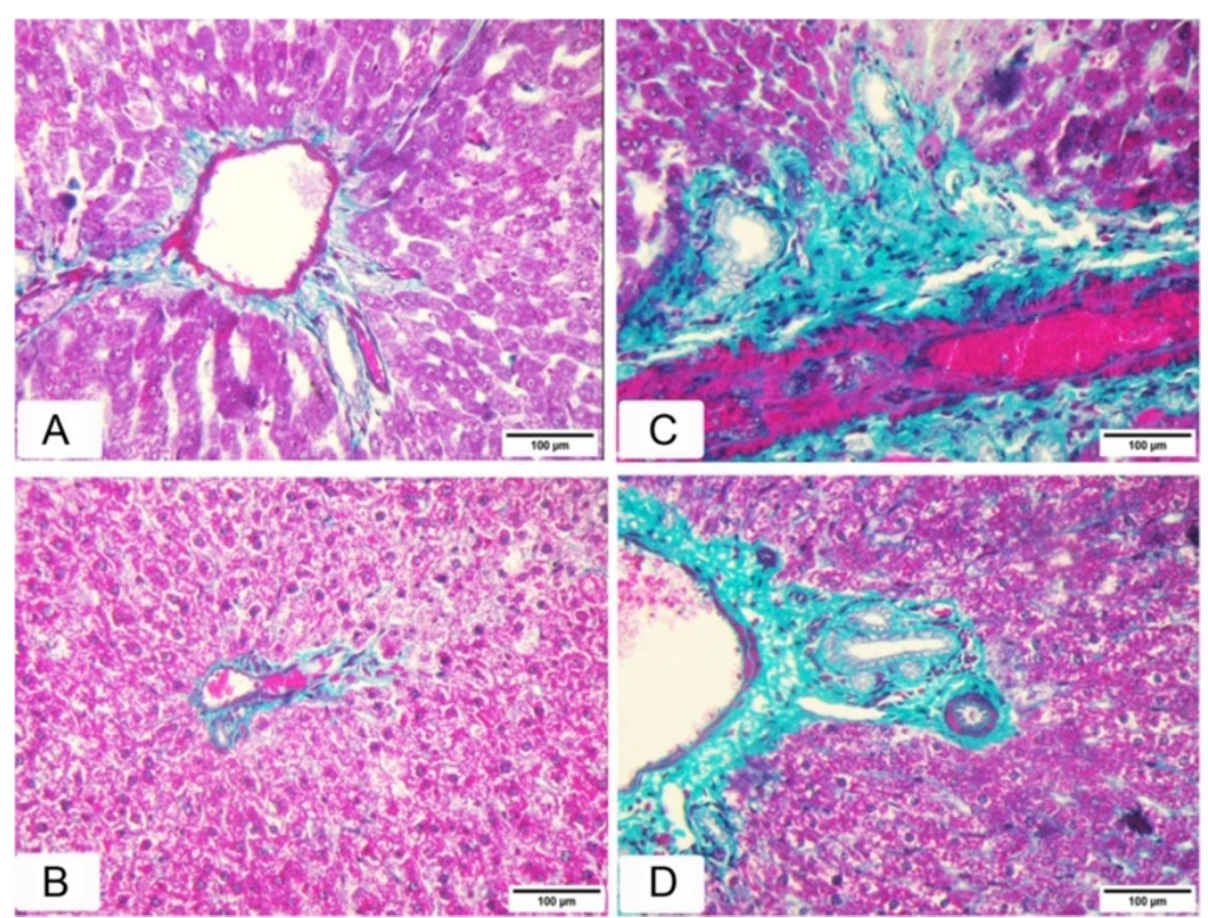

Fig. 4 Masson's Trichrome staining of collagen within the liver tissue. a, b Shows normal distribution of collagen fibers, stained green, around a portal tract in control and MUL-treated group, respectively. c Shows marked increase in collagen fibers around the blood vessels in the portal tract in MTX-treated group. d Shows normal distribution of collagen fibers, stained green, around a portal tract in MUL-MTX group, (Masson's trichrome, $\times 200$ )

MTX caused increased AST, ALT, ALP and LDH activities. These results are in agreement with Tunali-Akbay et al. [27] who demonstrated that rats treated with MTX exhibited a toxic effect on liver where it provoked a notable elevation in serum activities of ALT and AST. ALT is a cytosolic enzyme of the hepatocyte and its increased serum activity reflects a leakage in plasma membrane permeability, which in turn, associated with cell death. ALT is considered to be one of the best indicators of liver necrosis [28]. Many authors describe the mechanism through which MTX induced hepatotoxicity. Jahovic et al. [26] and Al-motabagani et al. [29] reported that MTX can bind to the enzyme hydrofolic reductase, which bans

Table 2 Morphometric quantitative measurements of liver fibrosis in animal groups stained with Masson's trichrome stain

\begin{tabular}{ll}
\hline Groups & Area \% \\
\hline Control & $1.33 \pm 1.51$ \\
Mulberry-Treated & $1.22 \pm 0.92$ \\
MTX-treated & $19.50 \pm 6.69^{\mathrm{a}}$ \\
Mulberry + MTX & $2.64 \pm 2.15^{\mathrm{b}}$ \\
\hline
\end{tabular}

Area \%: represent the degree of hepatic fibrosis, the results are represented as mean value $\pm \mathrm{SE}$

${ }^{\mathrm{a}}$ Significantly different from control using one way ANOVA followed by Duncan

${ }^{\mathrm{b}}$ Significantly different compared with MTX-treated group using one way ANOVA followed by Duncan conversion of folic acid to folinic acid causing block in some amino and nucleic acids synthesis. This might lead to damage of organelles and plasma membranes of hepatic parenchymal cells interfering with their function and allowing leakage of enzymes. Moreover, Kose et al. [30] stated that MTX caused increasing in malondialdehyde (MDA) and myeloperoxidase (MPO) levels leading to lipid peroxidation which is considered to be an important cause of destruction and damage to cell membranes, which has been suggested to be a contributing factor to the development of methotrexate-mediated tissue damage.

The present biochemical results suggest that MTX injection did not affect levels of TP, ALB and A/G ratio. The results from MTX treated groups was similar to those from the MUL+MTX treated group and control group. This could be possibly explained as Doumas and Peters [31] reported that any decrease of serum TP and ALB levels might indicate insufficient hepatocyte biosynthesis. One of the major reasons for a decline in biosynthetic functions is the low protein feeding diet. However, hence animals in the present study were fed a diet with suitable protein content, may be the cause of weaker variation in serum TP and ALB levels.

The biochemical changes induced by MTX treatment were confirmed by morphometeric and histological studies. 
Hepatosomatic index (HSI), is fundamental to liver injury diagnoses [32]. The liver indices of the experimental rats were noticeably affected by MTX treatment and regular oral administration of mulberry leaves extract. The results from this study show significantly higher HSI in MTXtreated rats when compared to control. This increase in liver weight may be probably due to formation of reactive oxygen species (ROS) which lead to hepatic damage [33] and liver inflammation [34]. MTX leaded to histopathological changes including hydropic degeneration, cellular infiltration and collagen deposition. These results are confirmed with other previous studies. Soliman [35] demonstrated that rats received a single injection of MTX (20 mg/kg, i.p.), exhibited a toxic effect on liver with plenty of focal sinusoidal areas, portal track inflammation, proliferation of Kupffer cells, focal liver cell necrosis, fibrosis and fatty changes in hepatocytes. Regarding, the Masson's Trichrome staining, there was a progressive increase of collagen deposition after MTX injection. The present observation is in agreement with those of Ros et al. [36] who found perisinusoidal fibrosis due to direct toxic effects of MTX. Also, Hytiroglou et al. [37] stated that the MTX is known to cause hepatic fibrosis in some patients, which might progress to cirrhosis. MTX is known to cause lipid peroxidation through generation of ROS which damage the mitochondrial and cytoplasmic membranes causing more severe oxidative damage in the tissues [27]. This liver cell injury usually initiate activation of blood-derived phagocytes that increases the concentration of fibrogenic cytokines and recruit a lot of fibroblasts and fibroblast-like cells for excess production of extracellular matrix [27, 38].

According to the present results, the in vitro level of MUL exhibited inhibition on HepG2 cell line proliferation with IC50 equal to $14.5 \mu \mathrm{g} / \mathrm{ml}$. These results are in agreement with previous results on HepG2 cells, showing that mulberry leaf extracts can inhibit cell proliferation and depress the levels of alpha-fetoprotein (AFP) and ALP in HepG2 cells than controls in a time dependent-manner [39], as well as through G2/M phase arrest and induction of apoptosis [40].

With regard to in vivo study, the administration of ethanolic mulberry leaves extract did not show any adverse affect on liver weight. The administration of MUL enhanced the hepatosomatic index of MTX treated rats and brought this parameter back to values very similar to that observed in the control group. Also, MUL given during the MTX application provided significant protection from the hepatotoxicity of MTX. Treatment with MUL in combination with MTX apparently exhibited a significant decrease in AST, ALT, ALP and LDH activities. Recently, Mallhi et al. [13] reported the hepatoprotective role of MUL on paracetamol induced liver injury in mice. Also, protective effect of MUL on rat liver injury in diabetic rats was demonstrated by Nazari et al. [41]. These studies showed that black mulberry administration prevented ALT and AST increase and improved liver function in diabetic rats. Moreover, Agha et al. [42] concluded that MUL juice possess antioxidant properties which could prevent liver dysfunction induced by $\mathrm{CCl} 4$. Thus, the possible mechanism may be due to free radical scavenger and antioxidant activities of MUL constituents, especially flavonoids (i.e., quercetin, rutin, and isoquercitrin) [43, 44]. According to the present results, liver sections of the rats treated with MUL at a dose of $500 \mathrm{mg} / \mathrm{kg}$ followed by MTX intoxication apparently ameliorated the gross and histological alterations in hepatic tissue induced by MTX. A possible mechanism of $M$. nigra extract as hepatoprotective may be due to its antioxidant effect, which can impair the activation of MTX into the reactive form. Since flavonoids have hepatoprotective activities [45]. Mulberry leaves were shown to contain at least four flavonoids, including rutin [44, 46, 47]. Flavonoids have long been recognized to possess hepatoprotective and anticarcinogenic activities [45, 48]. Moreover, leaves of mulberry plants have been recently reported to have antioxidant effect as they contain alkaloid as well as flavonoids Radojković et al. [43]. In the present work MUL administration to the MTX group significantly decreased the hepatic collagen content and histopathological score. This results may be due to the presence of flavonoids which known to possess remarkable antioxidant properties capable of protecting normal cells from various stimuliinduced oxidative stress and cell death [49]. The possible mechanism that is responsible for the protection of MTXinduced liver damage by mulberry leaves extract may be due to its radical scavenger activity. By trapping lipid and peroxyle radicals, MUL could hinder their interaction with polyunsaturated fatty acids and would abolish the enhancement of lipid per-oxidative processes [50].

Although Methotrexate is often the most effective agent for treating severe rheumatoid arthritis, hepatotoxicity is a frequent complication of long-term methotrexate therapy, and can force discontinuation of this drug [51]. According to considerations cited above likewise imply that MUL may be administered in conjunction with methotrexate therapy to encounter its oxidative effect.

\section{Conclusions}

In conclusion, the present study clearly demonstrates that MUL administration protected liver tissues, probably due to its antioxidant and cytoprotective characteristics. In addition, the administration of MUL could be used with chemotherapeutic agents in combination therapy with MTX-treatment.

Competing interests

The authors declare that he has no competing interests. 
Received: 25 February 2015 Accepted: 24 June 2015 Published online: 25 July 2015

\section{References}

1. Yuan L, Kaplowitz N. Mechanisms of drug-induced liver injury. Clin Liver Dis. 2013;17(4):507-18.

2. Kaplowitz N. Biochemical and cellular mechanisms of toxic liver injury. Semin Liver Dis. 2002;22:137-44.

3. Bayram M, Ozogul C, Dursun A, Ercan ZS, Isik I, Dilekoz E. Light and electron microscope examination of the effects of methotrexate on the endosalpinx. Eur J Obstet Gynecol Reprod Biol. 2005;120(1):96-103.

4. Vardi N, Parlakpinar H, Cetin A, Erdogan A, Ozturk C. Protective effect of $\beta$-carotene on methotrexate-induced oxidative liver damage. Toxicol Pathol. 2010;38:592-7.

5. Biernat J, Sendur R, Pawlik W, Brzozowski T. Dual role of sensory neuropeptides in methotrexate-induced liver damage. Pol Gastroenterol. 2010;17(3):208-12.

6. Issabeagloo E, Taghizadiyeh M, Kermanizadeh P. Hepatoprotective effect of taurine against oxidative stress due to methotrexate in rat. Am J Anim Vet Sci. 2011;6(4):187-92

7. Mukazayire MJ, Minani V, Ruffo CK, Bizuru E, Stévigny C, Duez P. Traditional phytotherapy remedies used in Southern Rwanda for the treatment of liver diseases. J Ethnopharmacol. 2011;138(2):415-31.

8. Özgen M, Serçe S, Kaya C. Phytochemical and antioxidant properties of anthocyanin-rich Morus nigra and Morus rubra fruits. Sci Hortic. 2009;119:275-9.

9. Memon AA, Memon N, Luthria DL, Bhanger MI, Pitafi AA. Phenolic acid profiling and antioxidant potential of mulberry (Morus laevigata, Morus nigra and Morus alba L.) leaves and fruits grown in Pakistan. Pol J Food Nutr Sci. 2010;60(1):25-32.

10. Naderi GA, Asgary S, Sarraf-Zadegan N, Oroojy H, Afshin-Nia F. Antioxidant activity of three extracts of Morus nigra. Phytother Res. 2004;18(5):365-9.

11. Mallhi TH, Qadir MI, Khan YH, Ali M. Hepatoprotective activity of aqueous methanolic extract of Morus nigra against paracetamol-induced hepatotoxicity in mice. Bangladesh J Pharmacol. 2014;9:60-6.

12. Malik MNH, Alamgeer US, Qayyum A, Samreen S. Phytochemical analysis and cardiac depressant activity of aqueous methanolic extract of Morus nigra L. Fruit. J Appl Pharm Sci. 2012;2:39-41.

13. Adedosu OT, Oyedeji AT, Iwaku T, Ehigie AF, Olorunsogo OO. Hepatoprotective activity and inhibitory effect of flavonoid-rich extract of Brysocarpus coccineus leaves on mitochondrial membrane permeability transition pore. Asian Journal of Natural \& Applied Sciences. 2014;3(3):92-100.

14. Mohammadi J, Prakash R, Naik O. The histopathologic effects of Morus alba leaf extract on the pancreas of diabetic rats. Turk J Biol. 2012;36:211-6.

15. Naowaboot J, Pannangpetch $P$, Kukongviriyapan V, Kukongviriyapan U, Nakmareong S, Itharatc A. Mulberry leaf extract restores arterial pressure in streptozotocin-induced chronic diabetic rats. Nutr Res. 2009;29:602-8.

16. Henriksson E, Kjellén E, Wahlberg P, Wennerberg J, Kjellström JH. Differences in estimates of cisplatin-induced cell kill in vitro between colorimetric and cell count/colony assays. In Vitro Cell Dev Biol Anim. 2006;42:320-3.

17. European Communities (EC). Council Directive $86 / 609 /$ EEC of 24 November 1986 on the approximation of laws, regulations and administrative provisions of the Member States regarding the protection of animals used for experimental and other scientific purposes. Off J Eur Communities. 1986;L 358, 18/12/1986:1-28.

18. Hemeida RAM, Mohafez OM. Curcumin attenuates methotraxate-induced hepatic oxidative damage in rats. J Egypt Natl Canc Inst. 2008;20(2):141-8.

19. Schumann G, Bonora R, Ceriotti F, Férard G, Ferrero CA, Franck PF, et al. IFCC primary reference procedures for the measurement of catalytic activity concentrations of enzymes at 37 degrees $C$. International Federation of Clinical Chemistry and Laboratory Medicine. Part 5. Reference procedure for the measurement of catalytic concentration of aspartate aminotransferase. Clin Chem Lab Med. 2002;40(7):725-33.

20. Young DS. Effects of drug on clinical laboratory test. 5th ed. Washington, DC: American Association for Clinical Chemistry, AACC Press; 2000

21. Tietz NW. Textbook of clinical chemistry. Philadelphia: W.B. Saunders; 1986.

22. Low D, Thomas NW, Fry JR. Lobar variation of carbon tetrachloride hepatotoxicity in the rat. Toxicol Lett. 1995;81:1-4.

23. Lobenhofer EK, Boorman GA, Phillips KL, Heinloth AN, Malarkey DE, Blackshear PE, et al. Application of visualization tools to the analysis of histopathological data enhances biological insight and interpretation. Toxicol Pathol. 2006;34:921-8.
24. Schneider CA, Rasband WS, Eliceiri KW. NIH Image to ImageJ: 25 years of image analysis. Nat Methods. 2012;9:671-5.

25. Sant'Anna LB, Sant'Anna N, Parolini O. Application of computer-assisted image analysis for identifying and quantifying liver fibrosis in an experimental model. J of Comput Interdiscip Sci. 2011;2(2):139-48.

26. Jahovic N, Çevik H, Şehirli AÖ, Yeğen BC, Şener G. Melatonin prevents methotrexate-induced hepatorenal oxidative injury in rats. J Pineal Res. 2003;34(4):282-7.

27. Tunali-Akbay T, Sehirli O, Ercan F, Sener G. Resveratrol protects against methotrexate-induced hepatic injury in rats. J Pharm Pharmaceut Sci. 2010;13(2):303-10.

28. Rosen HR, Keeffe EB. Evaluation of abnormal liver enzymes, use of liver test, and the serology of viral hepatitis. In: Bacon BR, Di Bisceglie AM, editors. Liver disease diagnosis and management. New York: Churchill; 2000. p. 24-35.

29. Al-motabagani MA. Histological and histochemical studies on the effects of mehotrexate on the liver of adult male albino rat. Int J Morphol. 2006;24(3):417-22.

30. Kose E, Irmak Sapmaz H, Sarihan E, Vardi N, Turkoz Y, Ekinci N. Beneficial effects of montelukast against methotrexate-induced liver toxicity: a biochemical and histological study. Sci Worl J. 2012;Article ID 987508:6. doi:10.1100/2012/987508.

31. Doumas BT, Peters T. Serum and urine albumin: a progress report on their measurement and clinical significance. Clin Chim Acta. 1997;258:3-20.

32. Saxena PN, Rathor S, Mahour K, Saxena N, Bajaj P. Alterations in hepatosomatic index and behaviour under Stress of arsenic trioxide and their modulation by curcuma Aromatica plant extract in albino rats (berkenhout). Pharmacol Online. 2010;1:243-51.

33. Kamat CD, Khandelwal KR, Bodhankar SL, Ambawade SD, Mhetre NA. Hepatoprotective activity of leaves of Feronia elephantum against carbon tetrachloride-induced liver damage in rats. J Natural Remde. 2003;3(2):148-54.

34. Moore KL, Dalley AF. Clinical oriented anatomy. Philadelphia: Woller Klumner Corporation; 1999.

35. Soliman ME. Evaluation of the possible protective role of folic acid on the liver toxicity induced experimentally by methotrexate in adult male albino rats Egypt. J Histol. 2009;32(1):118-28.

36. Ros S, Juanola X, Condom E, Canas C, Riera J, Guardiola J, et al. Light and electron microscopic analysis of liver biopsy samples from rheumatoid arthritis patients receiving long-term methotrexate therapy. Scand J Rheumatol. 2002;31(6):330-6

37. Hytiroglou P, Tobias H, Saxena R, Abramidou M, Papadimitriou CS, Theise $\mathrm{ND}$. The canals of hering might represent a target of methotrexate hepatic toxicity. Am J Clin Pathol. 2004;121(3):324-9.

38. Sheikh BY, Elsaed WM, Samman AH, Sheikh BY, Bin Ladin AM. Ajwa dates as a protective agent against liver toxicity in rat. Eur Scient J. 2014;3:1857-81.

39. Fathy SA, Singa AB, Agwa SA, Abd El Hamid DM, Zahra FA, Abd El Moneim SM. The antiproliferative effect of mulberry (Morus alba L.) plant on hepatocarcinoma cell line HepG2. Egy J Med Hum Genet. 2013;14:375-82.

40. Naowaratwattana W, De-Eknamkul W, De Mejia EG. Phenolic-containing organic extracts of mulberry (Morus alba L.) leaves inhibit HepG2 hepatoma cells through G2/M phase arrest, induction of apoptosis, and inhibition of topoisomerase II alpha activity. J Med Food. 2010;13:1045-56.

41. Nazari M, Hajizadeh MR, Eftekhar A, Fattahpour S, Ziaaddini H, Hassanshahi $\mathrm{G}$, et al. Comparative regulatory effects of Morus alba leaf extracts on hepatic enzymes in streptozotocin-induced diabetic and non-diabetic rats. Med Chem. 2014:S1:003. doi:10.4172/2161-0444.S1-003.

42. Agha FG, Fyiad AA, El Safi H. Comparative study of the protective role of black berry juice and silymarin against liver damage induced by carbon tetrachloride in rats. J Appl Sci Res. 2012;8(2):727-38.

43. Radojković MM, Zeković ZP, Vidović SS, Kočar DD, Mašković PZ. Free radical scavenging activity and total phenolic and flavonoid contents of mulberry (Morus spp. L., Moraceae) extracts. Hem Ind. 2012;66(4):547-52.

44. Katsube T, Imawaka N, Kawano Y, Yamazaki Y, Shiwaku K, Yamane Y. Antioxidant flavonol glycosides in mulberry (Morus alba L.) leaves isolated based on LDL antioxidant activity. Food Chem. 2006;97:25-31.

45. Ercisli S, Orhan E. Chemical composition of white (Morus alba), red (Morus rubra) and black (Morus nigra) mulberry fruits. Food Chem. 2007;103:1380-4.

46. Pawlowska AM, Oleszek W, Braca A. Quali-quantitative analyses of flavonoids of Morus nigra L. and Morus alba L. (Moraceae) fruits. J Agric Food Chem. 2008:56:3377-80

47. Mazimba O, Majinda RR, Motlhanka D. Antioxidant and antibacterial constituents from Morus nigra. Afr J Pharm Phamacol. 2011;5(6):751-4. 
48. Chaurasia S, Saxena RC, Chaurasia ID, Shrivastava R. Antidiabetic activity of Morus alba in streptozotocin induced diabetic rats. Int J Chem Sci. 2011;9(2):489-92.

49. Mukherjee S, Ghosh S, Choudhury S, Adhikary A, Manna K, Dey S, et al. Pomegranate reverses methotrexate-induced oxidative stress and apoptosis in hepatocytes by modulating Nrf2-NF-kB pathways. J Nutr Biochem. 2013;24(12):2040-50.

50. Kutlu T, Durmaz G, Ate B, Yilmaz I, Cetin MŞ. Antioxidant properties of different extracts of black mulberny (Morus nigra L.). Turk J Biol. 2011;5:103-10.

51. Gaies E, Jebabli N, Trabelsi S, Salouage I, Charfi R, Lakhal M, et al.

Methotrexate side effects: review article. J Drug Metab Toxicol. 2012;3:4. http://dx.doi.org/10.4172/2157-7609.1000125

\section{Submit your next manuscript to BioMed Central and take full advantage of:}

- Convenient online submission

- Thorough peer review

- No space constraints or color figure charges

- Immediate publication on acceptance

- Inclusion in PubMed, CAS, Scopus and Google Scholar

- Research which is freely available for redistribution 